\title{
Synthesis and properties of Nd-doped oxynitride phosphate laser glasses
}

\author{
Francisco Muñoz ${ }^{1, *}$, Akira Saitoh $^{2}$, Rafael J. Jiménez-Riobóo ${ }^{3}$, Rolindes Balda ${ }^{4,5}$ \\ ${ }^{1}$ Institute of Ceramics and Glass (CSIC), Madrid, Spain \\ ${ }^{2}$ Graduate School of Science and Engineering (Ehime University), Japan \\ ${ }^{3}$ Institute of Materials Science of Madrid (CSIC), Madrid, Spain \\ ${ }^{4}$ Applied Physics Department, Faculty of Engineering, University of the Basque Country \\ UPV/EHU, Bilbao, Spain \\ ${ }^{5}$ Materials Physics Centre CSIC-UPV/EHU, San Sebastian, Spain
}

*Corresponding author: $\underline{\text { fmunoz@icv.csic.es }}$

Instituto de Cerámica y Vidrio (CSIC), Kelsen 5, 28049 Madrid (Spain) 


\begin{abstract}
The substitution of nitrogen for oxygen in phosphate glasses improves the chemical, thermal and mechanical properties and particularly reduces their very high hygroscopic character, although the preparation of homogeneous and free of defects oxynitride bulk phosphate glasses through ammonolysis represents a big challenge. This work reports on the synthesis and properties of a series of Nd-doped oxynitride phosphate glasses with composition $\mathrm{Na}_{0.3} \mathrm{~K}_{0.3} \mathrm{Ba}_{0.2} \mathrm{PO}_{3-3 \mathrm{x} / 2} \mathrm{~N}_{\mathrm{x}}$ that may find application as laser hosts. Whereas the glass transition temperature, elastic modulus and index of refraction show a regular increase with the nitrogen content that agrees with previous studies, the effect of nitrogen onto the luminescence of $\mathrm{Nd}^{3+}$ ions appears to be more complicated. The average lifetime of the decay from the ${ }^{4} \mathrm{~F}_{3 / 2}$ level decreases with the N/P ratio of the glasses, which is thought to be mainly due to the presence of water from the ammonolysis reaction. However, further thermal treatments under $\mathrm{N}_{2}$ flow of an oxynitride glass have shown an important reduction of the water content as well as a drastic increase of the luminescence lifetime of $\mathrm{Nd}^{3+}$, this being a promising method for the development of laser phosphate glasses having good chemical and mechanical properties.
\end{abstract}

Keywords: Phosphate Glasses; Laser Glasses; Oxynitride Glasses; Nitridation; Neodymium 


\section{Introduction}

Phosphate glasses are known to possess large emission cross sections and low non-linear refractive indices, which are ideal for their application as solid state matrices for the emission of laser radiation. However, the use of glasses as laser hosts requires the production of generally large dimensions with a very high optical homogeneity and high quantum efficiencies, thus needing of very special processing conditions and a strict control of the glass composition. In particular, the refractive index change within the blanks must be less than $2 \times 10^{-6}$ and the absorption coefficient of the $\mathrm{OH}$ groups reduced to less than $5 \mathrm{~cm}^{-1}$. Additionally, the melting of phosphate glasses may also imply certain difficulties such as those regarding high volatility of their constituents, easiness of devitrification and rapid change of the viscosity with temperature due to their higher fragile character [1]. Nevertheless, neodymium containing phosphate glasses have been successfully applied for the production of high energy laser radiation in several projects, like the National Ignition Facility (NIF) at the Lawrence Livermore Laboratory, in USA, the Gekko-XII in Osaka, Japan, and the Shenguang projects in China [2]. Currently, there is a need for developing new glasses to serve as hosts for lasers of very high average power and high repetition rate. Furthermore, the ability to choose the right composition as well as the adequate processing conditions for their preparation, lie in the precise knowledge of the atomic structure and its influence on the glass properties.

From the chemical point of view, the main constituent in laser glass compositions that provides chemical resistance and mechanical strength is aluminium [3]. Despite its advantages, alumina reduces the emission cross-section, thus being a drawback that must be taken under consideration when designing novel compositions. $\mathrm{K}_{2} \mathrm{O}$ has been taken as the best modifier in view of its excellent characteristics to achieve large emission cross-section, 
long fluorescence lifetime and narrow emission band-width; however it is usual to add into the formulation other modifying oxides, such as $\mathrm{MgO}$ and $\mathrm{BaO}$, to stabilize the glasses [4].

An alternative to have a great improvement in chemical resistance and mechanical stability of the glasses is the partial substitution of nitrogen for oxygen. This method has been studied in many glass compositions although most of them are single or mixed alkali- and alkaline-earth based glasses and is performed through a thermal treatment of the base phosphate glass under a constant $\mathrm{NH}_{3}$ flow [5]. However, the glasses must not contain alumina in order to be able to have phosphate melts that keep viscosity values below $10 \mathrm{~Pa} . \mathrm{s}$ at the typical temperatures of the nitridation, that range between 600 and $800{ }^{\circ} \mathrm{C}$ [6]. Unlike the nitridation in phosphate glasses, the introduction into silicate systems by ammonolysis reaction gives rise to low nitrogen contents and it usually proceeds through the melting of glass batches with nitride raw materials such as $\mathrm{Si}_{3} \mathrm{~N}_{4}$, but this originates coloured, non-transparent and even partly crystallized samples [7]. Phosphate glasses are then thought to be good candidates for the development of oxynitride systems in which relatively low amounts of nitrogen introduced by ammonolysis may produce substantial changes in the chemical and mechanical properties with no need of adding $\mathrm{Al}_{2} \mathrm{O}_{3}$.

The structure of oxynitride phosphate glasses has been well studied, particularly through Nuclear Magnetic Resonance and X-ray Photoelectron spectroscopies. It is built up of $\mathrm{PO}_{3} \mathrm{~N}$ and $\mathrm{PO}_{2} \mathrm{~N}_{2}$ tetrahedra that have been formed from the $\mathrm{PO}_{4}$ groups of the oxide phosphate network [8]. On the other hand, nitrogen atoms may be bonded either to two or three phosphorus central atoms, in the form of di-coordinated $(-\mathrm{N}=)$ and tri-coordinated $(-\mathrm{N}<)$ species, respectively [9]. As a result, the bonding density and strength of the network increase significantly being at the source of the important improvement of the glass properties. So far, the majority of studies on the nitridation of phosphate glasses have concentrated on the structure and reaction mechanisms [10] and basic glass properties, whereas most recently the 
liquid fragility and pressure effects on their properties have concentrated the biggest efforts $[11,12]$.

Oxynitride phosphate glasses have been mostly studied as glasses for sealing applications [13], due to their low softening temperatures and good chemical durability. Furthermore, they have also been interesting as solid state electrolytes for all-solid-state lithium batteries, due to the fact that the ionic conductivity of lithium phosphate glasses increased with the nitrogen content [14], or as bioresorbable materials thanks to the control that is possible to be exerted on their dissolution behaviour through the nitrogen content [15]. However, there is only one report on the use of $\mathrm{Nd}^{3+}$ doping ions as a local structural probe in nitrided $\mathrm{NaPO}_{3}$ glasses [16].

In this work, we report on the preparation of transparent $\mathrm{Nd}_{2} \mathrm{O}_{3}$-doped oxynitride phosphate glasses from the system of composition $\mathrm{Na}_{2} \mathrm{O}-\mathrm{K}_{2} \mathrm{O}-\mathrm{BaO}-\mathrm{P}_{2} \mathrm{O}_{5}$, and on their thermal, elastic and luminescence properties. We have been focused on a glass system that keeps low glass transition temperature due to the absence of alumina, while having relatively good optical performance for laser applications. The main objective was to study what are the most appropriate conditions of synthesis of oxynitride compositions aiming at developing phosphate laser glasses with low melting and transition temperatures.

\section{Experimental}

\subsection{Synthesis}

A metaphosphate base glass with composition $15 \mathrm{Na}_{2} \mathrm{O}-15 \mathrm{~K}_{2} \mathrm{O}-20 \mathrm{BaO}-50 \mathrm{P}_{2} \mathrm{O}_{5}(\mathrm{~mol} . \%)$ and doped with 0.5 wt. $\% \mathrm{Nd}_{2} \mathrm{O}_{3}$ was firstly obtained by the melt-quenching method. A batch of $100 \mathrm{~g}$ was prepared from reagent grade $\mathrm{Na}_{2} \mathrm{CO}_{3}, \mathrm{~K}_{2} \mathrm{CO}_{3}, \mathrm{BaCO}_{3}$ and $\left(\mathrm{NH}_{4}\right)_{2} \mathrm{HPO}_{4}$ and $\mathrm{Nd}_{2} \mathrm{O}_{3}$ raw materials and was calcined up to $400^{\circ} \mathrm{C}$ for $24 \mathrm{~h}$ in a porcelain crucible, then melted at $900^{\circ} \mathrm{C}$ for $2 \mathrm{~h}$ in air. A series of four oxynitride glasses were synthesized through 
ammonolysis treatment of glass pieces of the metaphosphate base glass at $650^{\circ} \mathrm{C}$ under a constant flow of anhydrous $\mathrm{NH}_{3}$ for reaction time lengths between 1 and $4 \mathrm{~h}$. Three of the samples were obtained from about $10 \mathrm{~g}$ of the base glass (1, 2 and $4 \mathrm{~h}$ ) while the fourth sample resulted from the nitridation of ca. $20 \mathrm{~g}$ of base glass. The reaction scheme is the same as the one used previously in several works and also described in details in reference [6]. It is worth noting that once the reaction with ammonia is stopped, the $\mathrm{NH}_{3}$ is switched to pure $\mathrm{N}_{2}$ current flow and the furnace is allowed to cool down at a free rate. Thus, the reducing atmosphere inside the furnace avoids a re-oxidation of the melt while above the glass transition temperature, and the obtained glass is annealed with no need of further treatment. The temperature was chosen to $650^{\circ} \mathrm{C}$ to be the highest temperature at which no significant presence of bubbles appeared in the final oxynitride glass. Usually, higher temperatures of treatment lead to higher nitrogen contents for the same time length although the optical quality of the glasses is considerably reduced. However, it is recommended that the temperature is as high as possible because a lower viscosity of the melt facilitates the reaction with ammonia. All glass samples presented good transparency and very few of visible bubbles.

One of the oxynitride glasses having intermediate nitrogen content was submitted to further thermal treatments under pure $\mathrm{N}_{2}$ flow at temperatures of 750 and $800^{\circ} \mathrm{C}$ for $3 \mathrm{~h}$. This was intended for studying the effect of melt fining on the infrared spectra, regarding the water absorption, and on the luminescence properties.

\subsection{Characterisation}

The composition of the phosphate base glass was analysed through X-ray Fluorescence Spectroscopy in a PANalytical MagicX 2400 spectrometer through the pearl method by mixing $0.3 \mathrm{~g}$ of glass with $5.5 \mathrm{~g}$ of $\mathrm{Li}_{2} \mathrm{~B}_{4} \mathrm{O}_{7}$. The analysed contents of the oxide components 
were between $\pm 1 \mathrm{~mol} \%$ of the nominal ones and no contamination by $\mathrm{SiO}_{2}$ or $\mathrm{Al}_{2} \mathrm{O}_{3}$ was found from the crucible.

The content of nitrogen in the oxynitride glasses was determined with a LECO TC-436 oxygen/nitrogen analyser using the inert gas fusion method. At least three analyses were done in the same conditions for each sample with $\sigma_{\mathrm{n}-1}=0.02$.

The glass transition temperature $\left(\mathrm{T}_{\mathrm{g}}\right)$ was determined by Differential Thermal Analysis (DTA) in a SEIKO 6300 ATD/TG analyser, using platinum crucibles and a heating rate of 10 K.min ${ }^{-1}$ under air, and obtained at the onset of the endothermic effect shown in the DTA patterns.

Density measurements were performed by the Archimedes method using kerosene as the immersion liquid.

Optical transmittance $T$ of the polished plates with thickness $d$ of about $1 \mathrm{~mm}$ was inspected using a conventional double beam spectrometer (Hitachi, U-4100). Then, spectral dependence of absorption coefficient $\alpha$ was calculated using equation (1):

$$
\mathrm{T} \approx(1-\mathrm{R})^{2} \cdot \exp (-\alpha \mathrm{d})
$$

where $R$ is the reflectivity that was evaluated from transmittance $(\approx 90 \%)$ in the near-infrared region.

The coefficient of absorption of hydroxyl ions was determined from the transmission FourierTransformed Infrared Spectra (FTIR) of the glass samples in between 450 and $5000 \mathrm{~cm}^{-1}$ in a Perkin-Elmer Spectrum 100 spectrometer. The coefficient of absorption of $\mathrm{OH}\left(\alpha_{\mathrm{OH}}\right)$ has been calculated from the FTIR spectra using equation (1) according to the method described in reference [17].

$$
\alpha_{\mathrm{OH}}=-\log \left(\mathrm{T}_{3000} / \mathrm{T}_{5000}\right) / \mathrm{t}
$$

where $T_{3000}$ and $T_{5000}$ are the transmission at 3000 and $5000 \mathrm{~cm}^{-1}$, respectively, and $\mathrm{t}$ the sample thickness in $\mathrm{cm}$. 
High Resolution Brillouin Spectroscopy (HRBS) was used to obtain information about the Young's modulus, Poisson's coefficient and refractive index of the phosphate and oxynitride phosphate glasses. The experimental setup is based on a Sandercock type $3+3$ Tandem FabryPérot spectrometer [18] and a DPSS laser $\left(\lambda_{0}=532 \mathrm{~nm}\right)$ was the visible light source. Two scattering geometries (90A and Backscattering) [19] were used in order to assess the elastic and optical properties of the samples. Glass samples tested were transparent as well as elastically and optically isotropic. Figure 1 shows graphically the meaning of the $90 \mathrm{~A}$ and Backscattering scattering geometries. The corresponding acoustic wave vectors are:

$$
\mathrm{q}^{90 \mathrm{~A}}=\frac{4 \pi \sqrt{2}}{\lambda_{0}} ; \mathrm{q}^{180}=\frac{4 \pi \mathrm{n}}{\lambda_{0}}
$$

where $\lambda_{0}$ stands for the laser wavelength and $\mathrm{n}$ for the refractive index of the sample. The sound propagation velocity $(\mathrm{v})$ results from the combination of the Brillouin frequency shift, $\mathrm{f}$, and the corresponding acoustic wave vector:

$$
\mathrm{v}^{90 \mathrm{~A}}=\frac{\mathrm{f}^{90 \mathrm{~A}} \lambda_{0}}{\sqrt{2}} ; \mathrm{v}^{180}=\frac{\mathrm{f}^{180} \lambda_{0}}{2 \mathrm{n}}
$$

In the absence of acoustic dispersion, for elastic isotropic media as glasses, these velocities must be identical and thus information about the refractive index of the investigated material can be obtained:

$$
n=\frac{\mathrm{f}^{180}}{\mathrm{f}^{90 \mathrm{~A}} \sqrt{2}}
$$

Two independent elastic constants $c_{11}$ and $c_{44}$ describe the elastic properties of elastically isotropic solids. They are coupled via the mass density to the shear and longitudinal sound propagation velocities in the media:

$$
c_{11,44}=\rho \cdot v_{\mathrm{L}, \mathrm{T}}^{2}
$$

It is thus straightforward to calculate from $\mathrm{c}_{11}$ and $\mathrm{c}_{44}$ the corresponding Young's modulus (E) and Poisson's coefficient (v) [20]: 


$$
E=c_{44} \frac{\left(3 c_{11}-4 c_{44}\right)}{\left(c_{11}-c_{44}\right)} ; v=\frac{\left(c_{11}-2 c_{44}\right)}{\left(2 c_{11}-2 c_{44}\right)}
$$

The steady-state emission spectra were recorded by exciting the samples with a continuous wave (cw) Ti:sapphire ring laser $\left(0.4 \mathrm{~cm}^{-1}\right.$ linewidth) in the $770-920 \mathrm{~nm}$ spectral range. The fluorescence was analysed with a $0.25 \mathrm{~m}$ monochromator, and the signal was detected by an extended IR Hamamatsu H10330A-75 photomultiplier and finally amplified by a standard lock-in technique. Lifetime measurements were obtained by exciting the samples with a Tisapphire laser pumped by a pulsed frequency-doubled Nd:YAG laser ( 9 ns pulse width), and detecting the emission with Hamamatsu H10330A-75 photomultiplier. Data were processed by a Tektronix oscilloscope.

\section{Results}

Table 1 gathers the composition of the base glass and oxynitride glasses, the conditions of ammonolysis reaction at $650^{\circ} \mathrm{C}$ (time and mass), density, molar volume and glass transition temperature of the samples.

Figure 2 shows the glass transition temperature (a) and the index of refraction, at $532 \mathrm{~nm}$ and $24.5^{\circ} \mathrm{C}$, of the base and oxynitride glasses against the nitrogen content as the N/P ratio. In both cases, a regular increase is observed with the content of nitrogen. The change in $T_{g}$ is of ca. $25^{\circ} \mathrm{C}$ between the oxide glass and the one with the highest $\mathrm{N} / \mathrm{P}$ ratio $(0.27)$, while the increase in $\mathrm{n}$ reaches 0.04 units $(2.4 \%)$. Previous studies on nitrogen-containing phosphate glasses, particularly alkali-phosphate systems, confirm the above behaviour $[13,21]$. The increase of $\mathrm{T}_{\mathrm{g}}$ is attributed to the increased covalent character of the P-N bonds with respect to the $\mathrm{P}-\mathrm{O}$ ones as well as the increase reticulation of the glass-network that is established through the doubly and triply bonded nitrogen species to phosphorus atoms of neighbouring 
phosphate chains. As a result, the density of the glasses increases and makes the refractive index to increase as well.

Figure 3 shows the elastic modulus (a) and coefficient of Poisson $v$ (b), as determined by means of Brillouin spectroscopy against the N/P ratio. The elastic modulus shows again a net increase with the nitrogen content having values between ca. 41 and $44 \mathrm{GPa}$ (ca. 7\%). The range of $\mathrm{E}$ for phosphate glasses may cover from 20 to almost 70 or $80 \mathrm{GPa}$ for some silicophosphate or alumino-phosphate compositions [22].

On the other hand, the coefficient of Poisson first shows a very small increase, and then it decreases with N/P ratio, particularly between 0.1 and 0.2 . As pointed out by Rouxel, the coefficient of Poisson is an indicator of the atomic packing density of a glass and is interpreted as the resistance of a material to a volume change with respect to a change in shape [22].

Figure 4 shows the UV-visible transmittance spectra for the oxide base glass and the oxynitride glasses as well as their absorption coefficient. Marked absorption peaks due to $\mathrm{Nd}^{3+}$ ions are observed in the visible region between wavelengths of 300 and $1000 \mathrm{~nm}$. Furthermore, broad absorption peaks due to overtone of $\mathrm{P}-\mathrm{OH}$ stretched vibration (fundamental $\sim 3000 \mathrm{~nm}$ of wavelength) and P-N bonds can also be seen about wavelengths of $\sim 1520 \mathrm{~nm}$ and $\sim 2180 \mathrm{~nm}$, respectively.

Figure 5 gathers the FTIR spectra in transmittance mode of the base and oxynitride glasses after ammonolysis. Absorption of water in phosphate glasses is characterized by strong bands around $3000 \mathrm{~cm}^{-1}$ and, as it can be seen in the spectrum of the base glass, the transmittance at this wave number is quite below $10 \%$. Furthermore, the oxynitride glasses show two strong additional bands at ca. 3800 and $4600 \mathrm{~cm}^{-1}$, which grow in intensity with the increase of the N/P ratio. Previous studies of X-ray Photoelectron Spectroscopy (XPS) on phosphorus oxynitride glasses prepared through the same method have shown that nitrogen species can 
be completely decomposed into the two types of coordinated to phosphorus bonds, $-\mathrm{N}=$ and $\mathrm{N}<$, and that no $\mathrm{N}-\mathrm{H}$ bonds can be detected in significant amounts [23]. However, some amount of $\mathrm{N}-\mathrm{H}$ bonds cannot considered negligible and, as also seen in phosphazene compounds, the absorption of N-H bonds could be detected through FTIR at ca. $3421 \mathrm{~cm}^{-1}$ [24]. On the other hand, it is thought that the absorption at around $4600 \mathrm{~cm}^{-1}$ may be due to the presence of free $\mathrm{OH}$ groups [25]. As the nitridation reaction proceeds through the release of $\mathrm{H}_{2} \mathrm{O}$ as a product of reaction [10], it would also be expected that the bubbles present in the glass may have a certain content of $\mathrm{H}_{2} \mathrm{O}$ that can also influence the FTIR spectra.

The ${ }^{4} \mathrm{~F}_{3 / 2} \rightarrow{ }^{4} \mathrm{I}_{11 / 2}$ steady-state fluorescence spectra were measured at room temperature for all glasses by exciting with a Ti-sapphire laser at $800 \mathrm{~nm}$ in resonance with the ${ }^{4} \mathrm{I}_{9 / 2} \rightarrow{ }^{4} \mathrm{~F}_{5 / 2},{ }^{2} \mathrm{H}_{9 / 2}$ absorption band. As can be seen in Fig. 6, the emission is broadened in a non-homogeneous way due to site-to-site variations in the local ligand field. The peak position $(\sim 1054 \mathrm{~nm})$ and effective linewidth $(\sim 22 \mathrm{~nm})$ for the laser transition do not change significantly when increasing nitrogen concentration; however, the emission intensity is reduced. The effective linewidth was calculated from the integrated fluorescence band for the ${ }^{4} \mathrm{~F}_{3 / 2} \rightarrow{ }^{4} \mathrm{I}_{11 / 2}$ emission divided by the peak intensity [26].

The decays of the ${ }^{4} \mathrm{~F}_{3 / 2}$ state were obtained by exciting with a pulsed Ti-sapphire laser at 800 $\mathrm{nm}$ in the ${ }^{4} \mathrm{I}_{9 / 2} \rightarrow{ }^{4} \mathrm{~F}_{5 / 2}$ absorption band. Fig. 7 shows the logarithmic plot of the experimental decays of the ${ }^{4} \mathrm{~F}_{3 / 2}$ level as a function of the N/P ratio. As can be observed, the decay of the base glass is nearly single exponential whereas the decays of the oxynitride glasses deviate from a single exponential function. Moreover, as it is shown in Fig. 8, the nitrogen incorporation after the ammonolysis reaction does produce a strong decrease of the average life time of neodymium from 300 to $83.7 \mu$ s as the N/P ratio increases from 0 to 0.27 , respectively. The lifetime value for the oxynitride glasses corresponds to the average lifetime defined by $\langle\tau\rangle=\frac{\int I d t}{I_{\max }}$, where $\mathrm{I}(\mathrm{t})$ is the intensity at time t. The inset in Fig. 8 shows the values 
of the coefficient of absorption of hydroxyl ions, as calculated through equation (2), in the base glass and oxynitride glasses. Such a strong reduction in the lifetime values along with the N/P ratio must be in close relationship with the presence of water as seen by FTIR. Not only the mode at about $3000 \mathrm{~cm}^{-1}$ but the two found at wavenumbers between 3500 and 5000 $\mathrm{cm}^{-1}$ may contribute to the quenching of the lifetimes of $\mathrm{Nd}^{3+}$ ions.

As a means of studying the way it is possible to reduce the water from the oxynitride melt, the glass with $\mathrm{N} / \mathrm{P}=0.14$ was submitted to two further thermal treatments under a constant $\mathrm{N}_{2}$ flow. Any additional thermal treatment of an oxynitride glass needs to be done under reducing conditions in order to avoid the re-oxidation of the glass with the loss of nitrogen. The additional treatments were performed at $750^{\circ} \mathrm{C}$ and $800^{\circ} \mathrm{C}$ for $3 \mathrm{~h}$, and the results of the IR transmission on the two last samples can be seen in the spectra of Fig. 9 and compared with the spectrum of the base glass. The transmittance at $3000 \mathrm{~cm}^{-1}$ is very similar for the oxynitride glass with $\mathrm{N} / \mathrm{P}=0.14$ and the same after treatment under $\mathrm{N}_{2}$ at $750^{\circ} \mathrm{C}$; however, there is a strong increase in the transmittance for the glass after treatment at $800^{\circ} \mathrm{C}$. Furthermore, increasing the treatment temperature does also reduce the absorption bands between 3500 and $5000 \mathrm{~cm}^{-1}$, which indicates again a strong reduction in the content of water in the glass. The calculated coefficients of absorption of $\mathrm{OH}$ ions are 20.5 and $4.6 \mathrm{~cm}^{-1}$, for the samples after treatment at 750 and $800^{\circ} \mathrm{C}$, respectively.

The effect of the thermal treatment under $\mathrm{N}_{2}$ flow on the experimental decays of the ${ }^{4} \mathrm{~F}_{3 / 2}$ state can be observed in Fig. 10. The sample treated at $750^{\circ} \mathrm{C}$ for $3 \mathrm{~h}$ shows a decay that deviates from a single exponential function at short time although with a lifetime of $214 \mu \mathrm{s}$ whereas the sample treated at $800^{\circ} \mathrm{C}$ for $3 \mathrm{~h}$ shows a single exponential decay and a lifetime of $323 \mu \mathrm{s}$; a value which is even higher than the lifetime value of the base phosphate glass. 


\section{Discussion}

Unlike transport properties such as chemical dissolution or ionic conductivity, the elastic properties of the oxynitride phosphate glasses have not yet been studied in detail, although the variations with nitrogen are supposed to be in agreement with the modifications in density or hardness. In the case of phosphate laser glasses, the elastic modulus takes average values between 47 and $70 \mathrm{GPa}$ [2], but all having important contents of $\mathrm{Al}_{2} \mathrm{O}_{3}$ in their compositions, which additionally gives rise to a big increase in chemical and mechanical resistance but with reduction of the emission cross-sections of $\mathrm{Nd}^{3+}$ ions. In the glasses studied in this work, the nitrogen contents are in the best case of $\mathrm{N} / \mathrm{P}=0.27$, which already results in a $10 \%$ increase in the elastic modulus. It is then expected that higher nitrogen contents or, alternatively, oxynitride glasses produced from glass compositions with different modifier cations and in different proportions may reach even higher values of $E$ after proper nitridation conditions.

On the other hand, the coefficient of Poisson in oxide glasses ranges between 0.1 and 0.4 and is directly depending on the polymerization degree of the network. Highly polymerized systems with $3 \mathrm{D}$ structures, such as vitreous silica, possess Poisson's ratio of ca. 0.15 , while networks that are built up of chains or rings have values higher than 0.3 . The decrease observed for $v$ at intermediate nitrogen contents in the present glasses should be directly related to the increased cross-linking density of the oxynitride network after nitridation. However, the very similar value of glass with $\mathrm{N} / \mathrm{P}=0.13$ and the pure oxide glass falls out of the trend for higher N/P values and should be explained attending to other factors. One of them might be related to the fact that small nitrogen contents may result in glasses where oxynitride regions are segregated within the pure oxide phosphate glass matrix, as it was proposed by Paraschiv et al. when studying the liquid fragility behaviour of lithium and sodium oxynitride phosphates [11]. 
Concerning the optical properties of the oxynitride glasses, they show adequate optical transmittance (>85\%) at around wavelengths of $1000 \mathrm{~nm}$, and are therefore good candidates for the design of solid state laser hosts. However, as seen from FTIR spectra, the nitridation itself produces a detrimental effect on the luminescence properties of the glasses due to the presence of water after reaction with $\mathrm{NH}_{3}$. Furthermore, there may be a number of different factors that can be involved simultaneously and should be taken into account in order to explain the luminescence behaviour. The characteristic decay time of the ${ }^{4} \mathrm{~F}_{3 / 2}$ level should be governed by a sum of probabilities for radiative and non-radiative processes. The nonradiative processes include $\mathrm{Nd}-\mathrm{Nd}$ self-quenching, non-radiative multi-phonon relaxation, and quenching induced by impurities. Non-radiative decay by multi-phonon emission is expected to be small because the energy difference between ${ }^{4} \mathrm{~F}_{3 / 2}$ and ${ }^{4} \mathrm{I}_{15 / 2}$ levels is around $5500 \mathrm{~cm}^{-1}$ and the highest phonon energy is about $1100 \mathrm{~cm}^{-1}$ [27]. This corresponds to 5 phonons, which indicates that multi-phonon relaxation process is weak and it could be neglected in this case. The Nd-Nd self-quenching should be the same for all glasses since they have all the same $\mathrm{Nd}^{3+}$ concentration. Therefore, the quenching induced by impurities seems to be the main responsible for the lifetime behavior as the N/P ratio increases, and particularly considering the fact that some additional water remains inside the glasses as a product of the ammonolysis reaction, the non-radiative decay must be directly influenced by the presence of hydroxyl ions.

The calculated coefficient of absorption of hydroxyl ions has been found to be very similar for almost all oxynitride samples except for the glass with $\mathrm{N} / \mathrm{P}=0.14$, for which it reaches 44 $\mathrm{cm}^{-1}$, as it is seen in the inset of Fig. 8 . The rest fall in between 10 and $20 \mathrm{~cm}^{-1}$, approximately. We have attributed the higher absorption effect of hydroxyl ions to the fact that a higher amount of base glass has been used for the nitridation reaction. The effect of a bigger mass on nitridation is clearly seen by the lower amount of nitrogen incorporated inside the glass, a 1.6 
wt. $\%$ from $20 \mathrm{~g}$ of glass against $1.9 \mathrm{wt} . \%$ obtained in $10 \mathrm{~g}$ for $2 \mathrm{~h}$ treatment each. It seems reasonable then that a higher absorption of hydroxyl ions may give rise to a bigger decrease of the neodymium luminescence life time and, in fact, the glass with $\mathrm{N} / \mathrm{P}=0.14$ does have a smaller value of $\tau$ than the one with $\mathrm{N} / \mathrm{P}=0.17$. However, further increase in the nitrogen content still produces a decrease in the life time although the coefficient of absorption of hydroxyl ions is again lower for the glass with $\mathrm{N} / \mathrm{P}=0.27$.

The nitrogen content of the two glasses with $\mathrm{N} / \mathrm{P}=0.14$ and submitted to treatments under $\mathrm{N}_{2}$ flow was also analysed and we found a significant decrease as well. The results are now 1.01 wt. $\%$ and 0.77 wt. $\% \mathrm{~N}$, for the samples treated at $750^{\circ} \mathrm{C}$ and $800^{\circ} \mathrm{C}$, respectively. On the other hand, the $\mathrm{T}_{\mathrm{g}}$ of the glasses treated in $\mathrm{N}_{2}$ as determined by DTA in the same conditions revealed a small decrease, resulting in $309^{\circ} \mathrm{C}$ and $312^{\circ} \mathrm{C}$, respectively for $750^{\circ} \mathrm{C}$ and $800^{\circ} \mathrm{C}$ treatment temperatures. The change is in average of ca. $5^{\circ} \mathrm{C}$ and should be attributed to the loss of nitrogen observed after the thermal treatment under $\mathrm{N}_{2}$ flow, that would result in a decrease of $T_{\mathrm{g}}$, simultaneously to the dihydroxylation of the glasses at the treatment temperatures.

The increase of the lifetime of $\mathrm{Nd}^{3+}$ after the thermal treatments under $\mathrm{N}_{2}$ indicates a suppression of non-radiative relaxation due to the significant reduction of $\mathrm{OH}$ groups. The content of $\mathrm{OH}$ groups in the glasses is thus an important factor to control since it has a negative effect on the luminescence efficiency producing a lifetime shortening. The high vibration frequency of these groups increases the probability of multi-phonon energy transfer processes from $\mathrm{Nd}^{3+}$ to $\mathrm{OH}$ vibrations which leads to non-radiative quenching of the $\mathrm{Nd}^{3+}$ fluorescence. Despite the observed reduction of the nitrogen in the glass for the treatment at $800^{\circ} \mathrm{C}$, we have been able to prepare an oxynitride glass with enhanced luminescence properties. Further work is currently under progress in order to improve the synthesis methodology and study the effect of the dehydration treatments on the chemical composition 
and structure of the oxynitride phosphate glasses, which has been seen to be a key issue to optimize the luminescence properties of these glasses to be used as laser materials.

\section{Conclusions}

The adequate combination of moderate temperatures and time lengths of ammonolysis have demonstrated the ability for the preparation of transparent and homogeneous Nd-doped oxynitride phosphate glasses. The glass transition temperature, elastic modulus and refractive index of glasses with compositions $\mathrm{Na}_{0.3} \mathrm{~K}_{0.3} \mathrm{Ba}_{0.2} \mathrm{PO}_{3-3 \mathrm{x} / 2} \mathrm{~N}_{\mathrm{x}} \quad(\mathrm{x}=0-0.27)$ present a regular increase with the N/P ratio as a consequence of the higher reticulation of the glass network introduced by the P-N bonds formed after ammonolysis. On the other hand, the influence of the $\mathrm{N} / \mathrm{P}$ ratio on the emission properties of $\mathrm{Nd}^{3+}$ ions has been investigated from the emission spectra of the ${ }^{4} \mathrm{~F}_{3 / 2} \rightarrow{ }^{4} \mathrm{I}_{11 / 2}$ laser transition and the decays from the ${ }^{4} \mathrm{~F}_{3 / 2}$ level. Whereas the

peak position and effective linewidth of the ${ }^{4} \mathrm{~F}_{3 / 2} \rightarrow{ }^{4} \mathrm{I}_{11 / 2}$ emission are nearly independent on the nitrogen content, the lifetimes are strongly reduced with the nitrogen incorporation. This problem can be overcome with thermal treatments under $\mathrm{N}_{2}$ flow to reduce the presence of $\mathrm{OH}$ that quenches the luminescence. The increase of the lifetime of the ${ }^{4} \mathrm{~F}_{3 / 2}$ state for the oxynitride glass with $\mathrm{N} / \mathrm{P}=0.14$ treated at $800^{\circ} \mathrm{C}$ for $3 \mathrm{~h}$ indicates a strong suppression of non-radiative relaxation due to the reduction of $\mathrm{OH}$ groups.

\section{Acknowledgements}

The authors thank funding from projects MAT2013-48246-C2-1-P, MAT2013-48246-C2-2-P and MAT2015-65356-C3-1-R from MINECO of Spain, Basque Country University for PPG17/07 and I-link+0959 from CSIC. One of the authors, RJJR, wants to thank Prof. Dr. J. K. Krüger form the Universität des Saarlandes (Germany) for providing a spare light source for the Brillouin Scattering experiments. 


\section{References}

[1] C.A. Angell, J. Non-Cryst. Solids, 131-133 (1991) 13-31.

[2] J. H. Campbell, J. S. Hayden and A. Marker, Int. J. App. Glass Sci., 2 (2011) 3-29.

[3] A. E. Marino S. R. Arrasmith, L. L. Gregg, S. D. Jacobs, G. Chen and Y. Duc, J. NonCryst. Solids, 289 (2001) 37-41.

[4] J. H. Campbell and T. I. Suratwala, J. Non-Cryst. Solids, $263 \& 264$ (2000) 318-341.

[5] R. Marchand, C.R. Acad. Sc. Paris 294 (1982) 91-94.

[6] F. Muñoz, A. Durán, L. Pascual and R. Marchand, Phys. Chem. Glasses 46 (2005) 39-45.

[7] S. Ali, B. Jonson, M.J. Pomeroy and S. Hampshire, Ceramics International 41 (2015) $3345-3354$.

[8] F. Muñoz, L. Montagne, L. Delevoye and T. Charpentier, J. Non-Cryst. Solids 363 (2013) 134-139.

[9] F. Muñoz, L. Pascual, A. Durán, R. Berjoan and R. Marchand, J. Non-Cryst. Solids 352 (2006) 3947-3951.

[10] F. Muñoz, Phys. Chem. Glasses: Eur. J. Glass Sci. Technol. B 52 (2011) 181-186.

[11] G. L. Paraschiv, F. Muñoz, L. R. Jensen, Y. Yue and M. M. Smedskjaer, J. Non-Cryst. Solids 441 (2016) 22-28.

[12] M. N. Svenson, G. L. Paraschiv, F. Muñoz, Y. Yue, S. J. Rzoska, M. Bockowski, L. R. Jensen and M. M. Smedskjaer, J. Non-Cryst. Solids 452 (2016) 153-160.

[13] F. Muñoz, L. Pascual, A. Durán and R. Marchand, Phys. Chem. Glasses 43C (2002) 113-118.

[14] B. Wang, B. S. Kwak, B. C. Sales and J. B. Bates, J. Non-Cryst. Solids 183 (1995) 297306.

[15] Q. Riguidel and F. Muñoz, Acta Biomaterialia 7 (2011) 2631-2636. 
[16] L. Boukbir, R. Marchand, Y. Laurent, C. J. Chao, C. Parent and G. Le Flem, Journal of the less-common metals 148 (1989) 327-331.

[17] H. Ebendorff-Heidepriem and D. Ehrt, Glastech. Ber. Glass Sci. Technol. 68 (1995) 139146.

[18] J. R. Sandercock, in Light Scattering in Solids III, ed. M. Cardona and G. Guntherdot, Springer-Verlag, Berlin, 1982.

[19] J. K. Krüger, in Brillouin Spectroscopy and its application to Polymers in Optical techniques to characterize polymer systems, ed. A. Bässler, Elsevier, Amsterdam, 1989.

[20] G. Grimvall, in Thermophysical Properties of Materials, ed. E. P. Wohlfarth, NorthHolland, Amsterdam, 1986.

[21] R. W. Larsson and D. E. Day, J. Non-Cryst. Solids 88 (1986) 97-113.

[22] T. Rouxel, J. Am. Ceram. Soc. 90(10) (2007) 3019-3039.

[23] F. Muñoz, L. Pascual, A. Durán, J. Rocherullé and R. Marchand, C. R. Chimie 5 (2002) 731-738.

[24] H. Dal and Y. Süzen, Spectrochimica Acta A 67 (2007) 1392-1397.

[25] M. Langlet, C. Coutier, W. Meffre, M. Audier, J. Fick, R. Rimet and B. Jacquier, J. Luminescence 96 (2002) 295-309.

[26] R. R. Jacobs and M. J. Weber, IEEE J. Quantum Electron. QE-10 (1976) 102-111.

[27] P. R. Ehrmann and J. H. Campbell, J. Am. Ceram. Soc. 85 (2002) 1061-69. 


\section{Figure captions}

Figure 1: Schematics of the Backscattering (180) and 90A scattering geometries. ki and ks correspond to the incident and scattered light wave vectors and $\mathrm{q}^{90 \mathrm{~A}}$ and $\mathrm{q}^{180}$ are the corresponding acoustic wave vectors.

Figure 2: Glass transition temperature in ${ }^{\circ} \mathrm{C}$ (a) and refractive index at $532 \mathrm{~nm}$ (b) of the oxynitride glass samples as a function of the N/P ratio.

Figure 3: Elastic modulus in GPa (a) and coefficient of Poisson (b) of the oxynitride glasses against the nitrogen content as the N/P ratio.

Figure 4: Optical transmittance spectra of the base and oxynitride phosphate glasses for wavelengths of 300-2500 $\mathrm{nm}$. The inset shows the absorption coefficient between 300 and $1000 \mathrm{~nm}$.

Figure 5: FTIR spectra of the oxynitride glass samples between 5500 and $1500 \mathrm{~cm}^{-1}$.

Figure 6: Room temperature emission spectra of the ${ }^{4} \mathrm{~F}_{3 / 2} \rightarrow{ }^{4} \mathrm{I}_{11 / 2}$ transition of $\mathrm{Nd}^{3+}$ ions in the base and oxynitride phosphate glasses doped with 0.5 wt. $\%$ of $\mathrm{Nd}_{2} \mathrm{O}_{3}$ obtained under excitation at $800 \mathrm{~nm}$.

Figure 7: Logarithmic plot of the experimental decays from the ${ }^{4} \mathrm{~F}_{3 / 2}$ state for the base and oxynitride phosphate glasses doped with 0.5 wt. $\%$ of $\mathrm{Nd}_{2} \mathrm{O}_{3}$. The decays were obtained by exciting at the ${ }^{4} \mathrm{I}_{9 / 2} \rightarrow{ }^{4} \mathrm{~F}_{5 / 2}$ transition and monitored at $1054 \mathrm{~nm}$.

Figure 8: Lifetime of the decay of the oxynitride glasses as a function of the N/P ratio. The inset shows the coefficient of absorption of hydroxyl ions in the glasses as calculated from the FTIR spectra $v s$. the N/P ratio.

Figure 9: FTIR spectra of the oxynitride glass with N/P $=0.14$ and those of the same glass after thermal treatment under $\mathrm{N}_{2}$ flow at $750^{\circ} \mathrm{C}$ and $800^{\circ} \mathrm{C}$ for $3 \mathrm{~h}$. 
Figure 10: Logarithmic plot of the experimental decays from the ${ }^{4} \mathrm{~F}_{3 / 2}$ state for the oxynitride glass with $\mathrm{N} / \mathrm{P}=0.14$ treated at $750^{\circ} \mathrm{C}$ for $3 \mathrm{~h}$ (black line) and at $800^{\circ} \mathrm{C}$ for $3 \mathrm{~h}$ (blue line) doped with 0.5 wt. $\%$ of $\mathrm{Nd}_{2} \mathrm{O}_{3}$.

\section{Table captions}

Table 1: Glass composition of the base glass and studied samples, wt. $\% \mathrm{~N}$ and N/P ratio, reaction conditions of nitrided samples, density, molar volume and glass transition temperature $\left(\mathrm{T}_{\mathrm{g}}\right)$. 
Table 1

\begin{tabular}{|l|c|c|c|c|c|c|}
\hline Glass & $\begin{array}{c}\text { time in } \mathrm{h} \\
\text { (mass in g) }\end{array}$ & $\%$ wt. N & $\begin{array}{c}\mathrm{N} / \mathrm{P} \\
( \pm 0.02)\end{array}$ & $\begin{array}{c}\mathrm{d}( \pm 0.001 \\
\text { g.cm }\end{array}$ & $\mathrm{V}_{\mathrm{m}}\left(\mathrm{cm}^{3} . \mathrm{mol}^{-1}\right)$ & $\mathrm{T}_{\mathrm{g}}\left( \pm 2{ }^{\circ} \mathrm{C}\right)$ \\
\hline $\mathrm{Na}_{0.3} \mathrm{~K}_{0.3} \mathrm{Ba}_{0.2} \mathrm{PO}_{3}$ & - & 0 & 0 & 2.924 & 45.44 & 300 \\
\hline $\mathrm{Na}_{0.3} \mathrm{~K}_{0.3} \mathrm{Ba}_{0.2} \mathrm{PO}_{2.81} \mathrm{~N}_{0.13}$ & $1(10 \mathrm{~g})$ & 1.46 & 0.13 & 2.926 & 44.97 & 313 \\
\hline $\mathrm{Na}_{0.3} \mathrm{~K}_{0.3} \mathrm{Ba}_{0.2} \mathrm{PO}_{2.79} \mathrm{~N}_{0.14}$ & $2(20 \mathrm{~g})$ & 1.62 & 0.14 & 2.932 & 44.83 & 316 \\
\hline $\mathrm{Na}_{0.3} \mathrm{~K}_{0.3} \mathrm{Ba}_{0.2} \mathrm{PO}_{2.75} \mathrm{~N}_{0.17}$ & $2(10 \mathrm{~g})$ & 1.90 & 0.17 & 2.931 & 44.76 & 318 \\
\hline $\mathrm{Na}_{0.3} \mathrm{~K}_{0.3} \mathrm{Ba}_{0.2} \mathrm{PO}_{2.59} \mathrm{~N}_{0.27}$ & $4(10 \mathrm{~g})$ & 3.10 & 0.27 & 2.946 & 44.18 & 326 \\
\hline
\end{tabular}




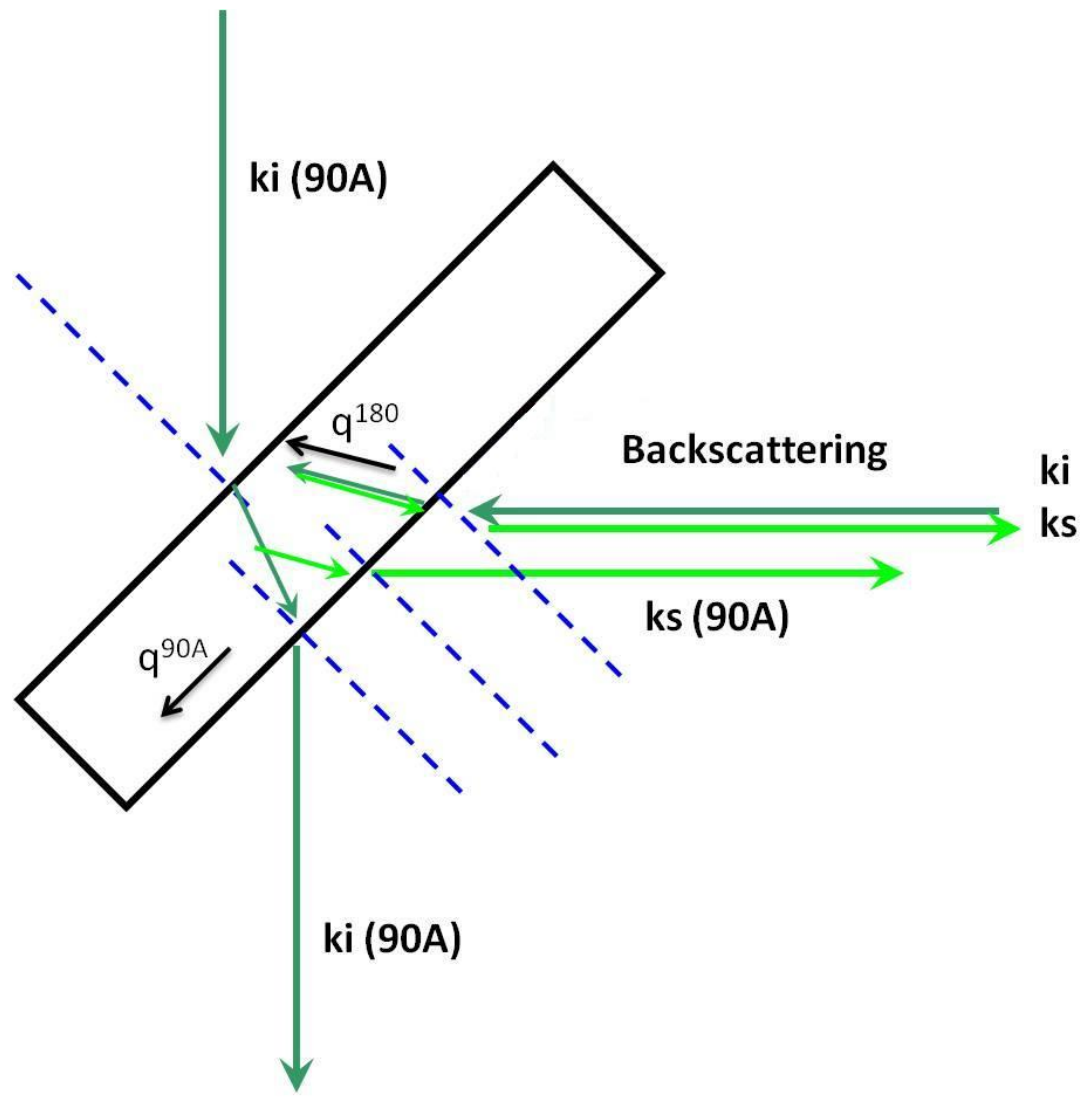

Figure 1 

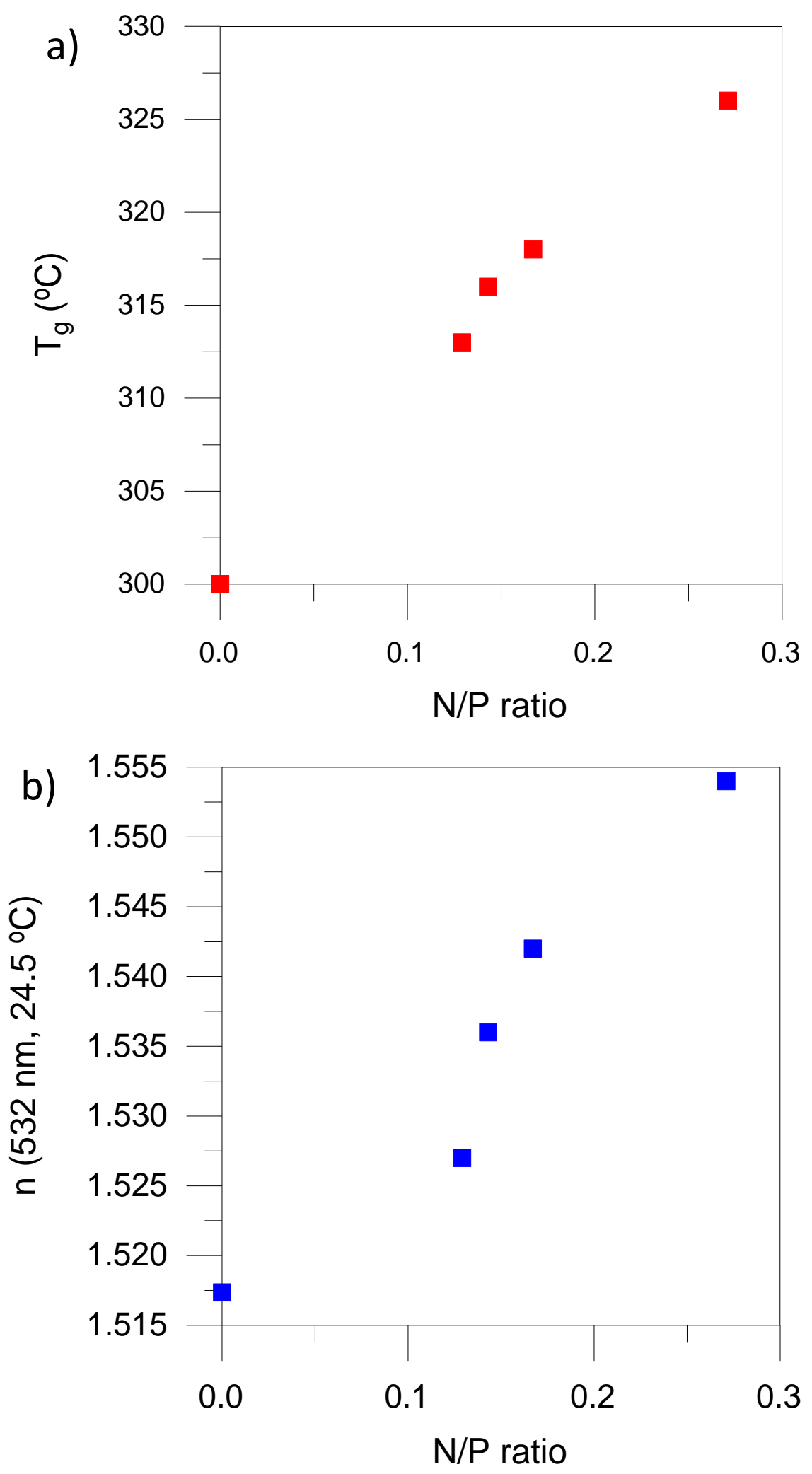

Figure 2 

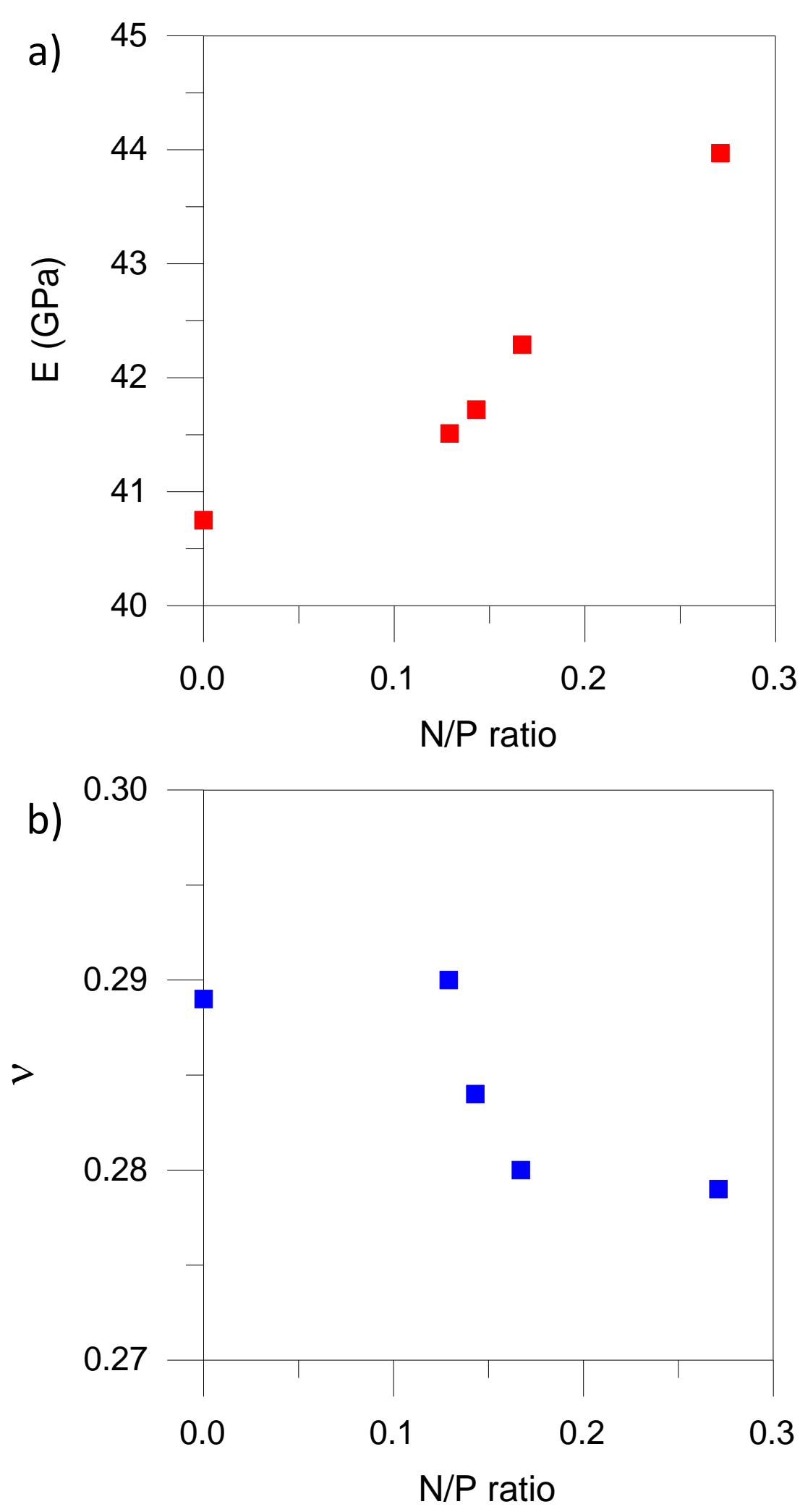

Figure 3 


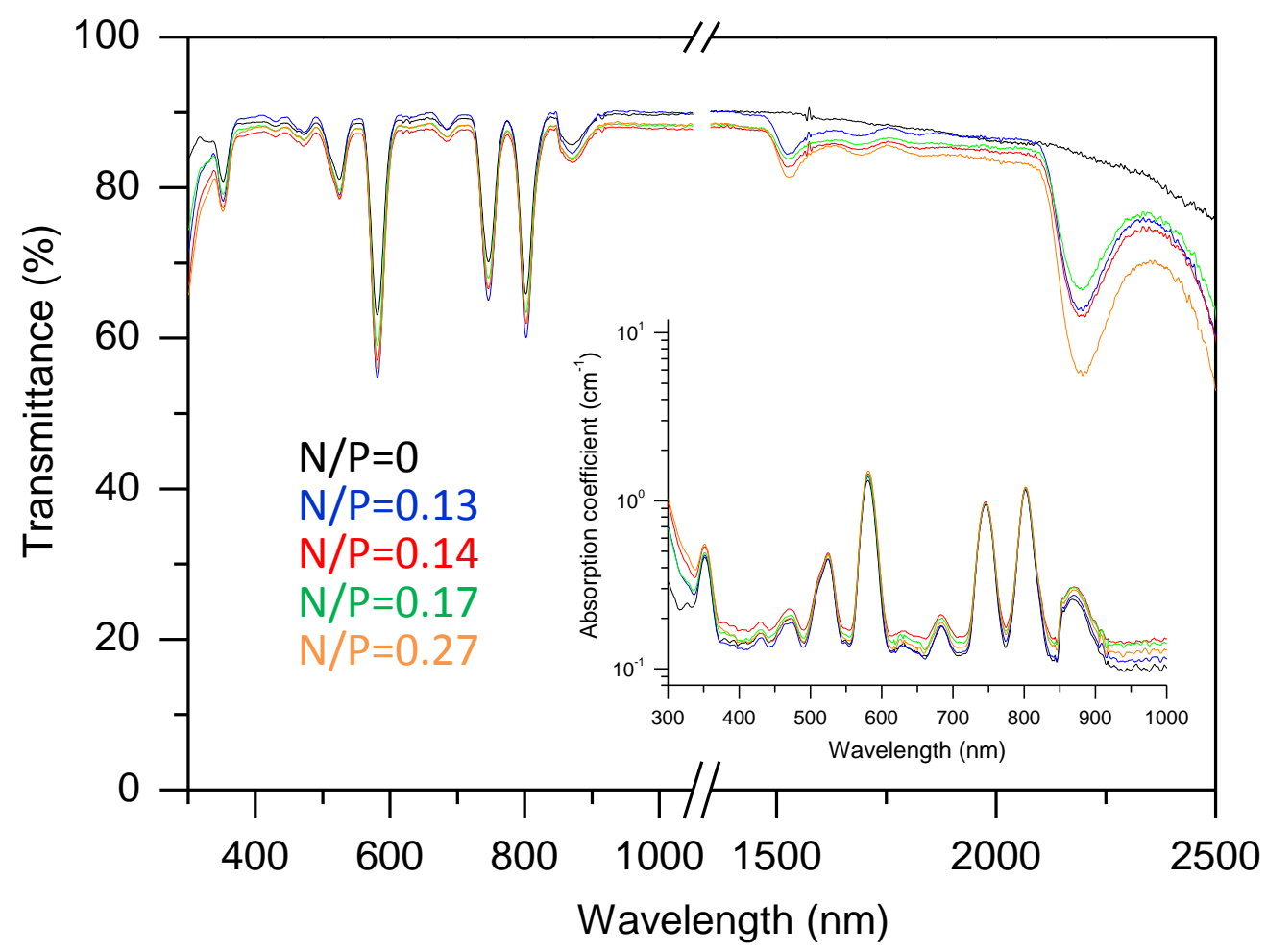

Figure 4 


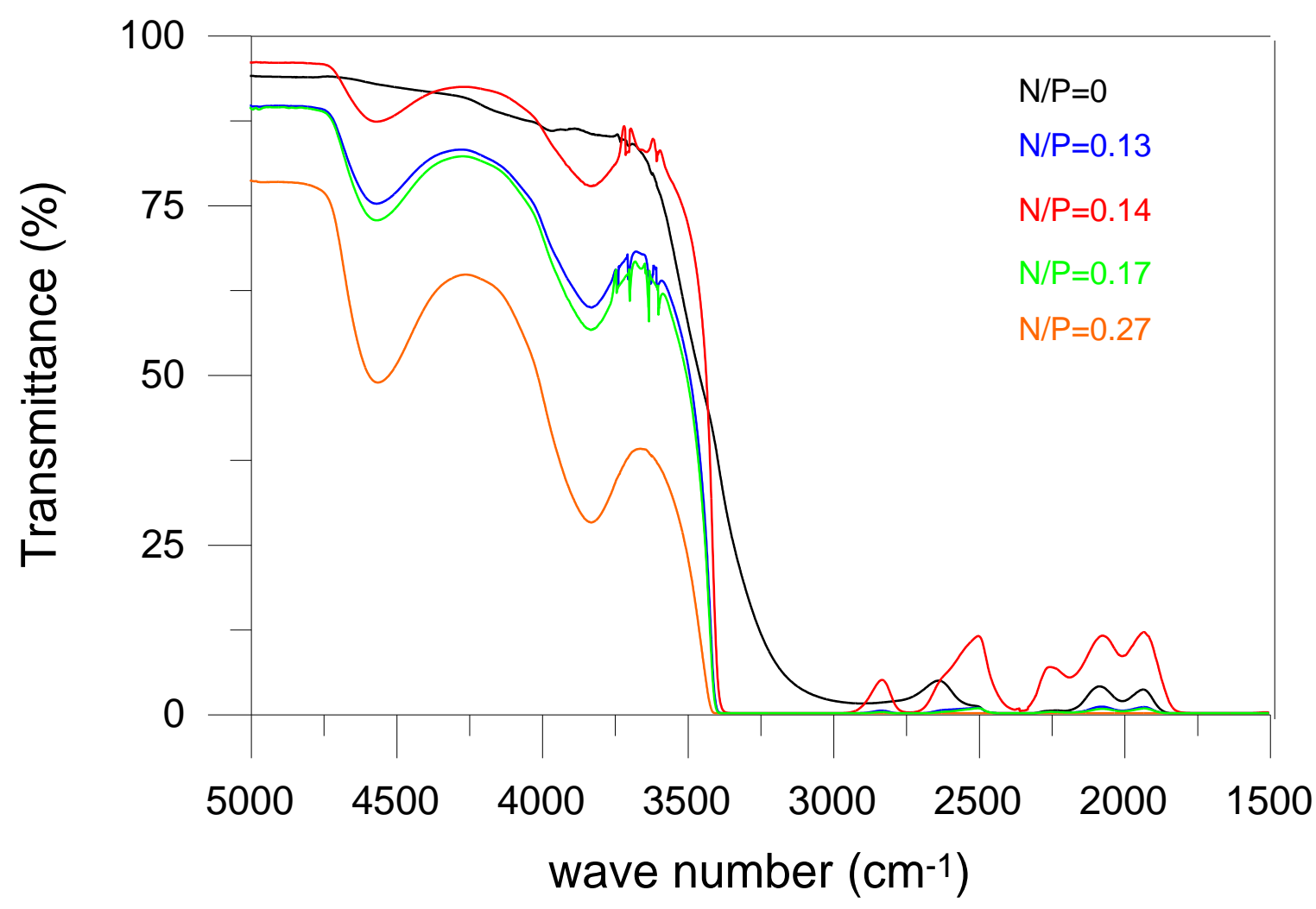

Figure 5 


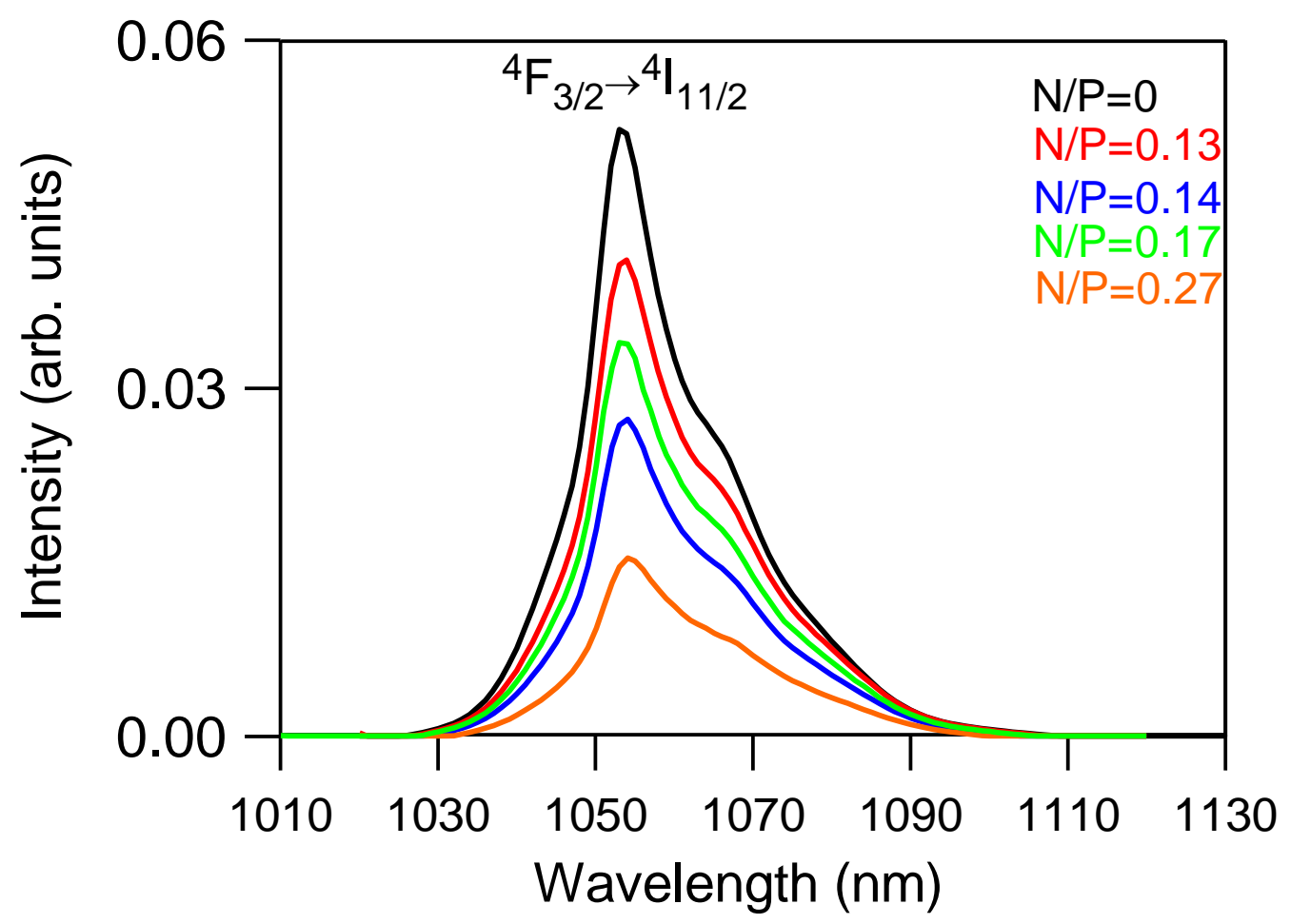

Figure 6 


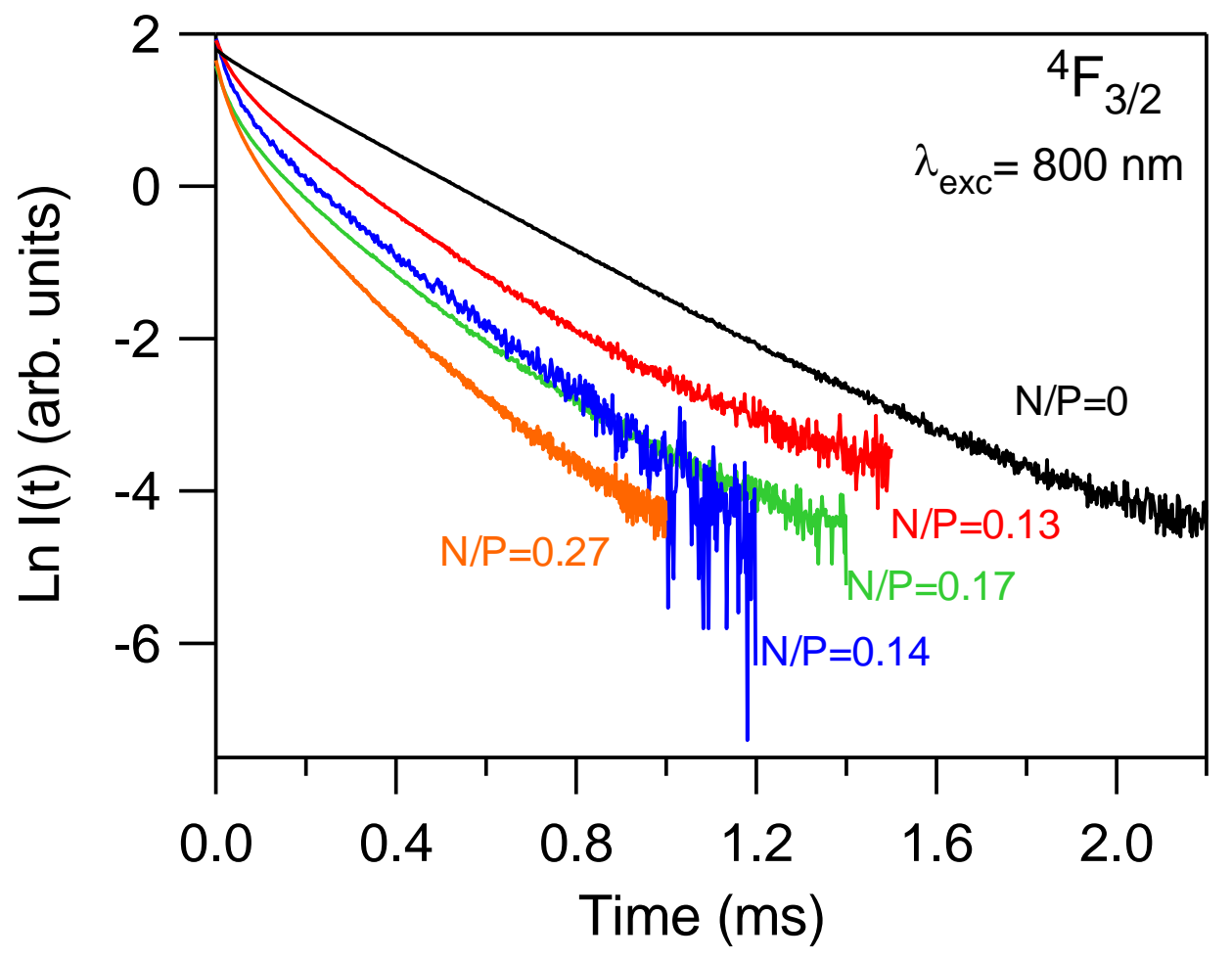

Figure 7 


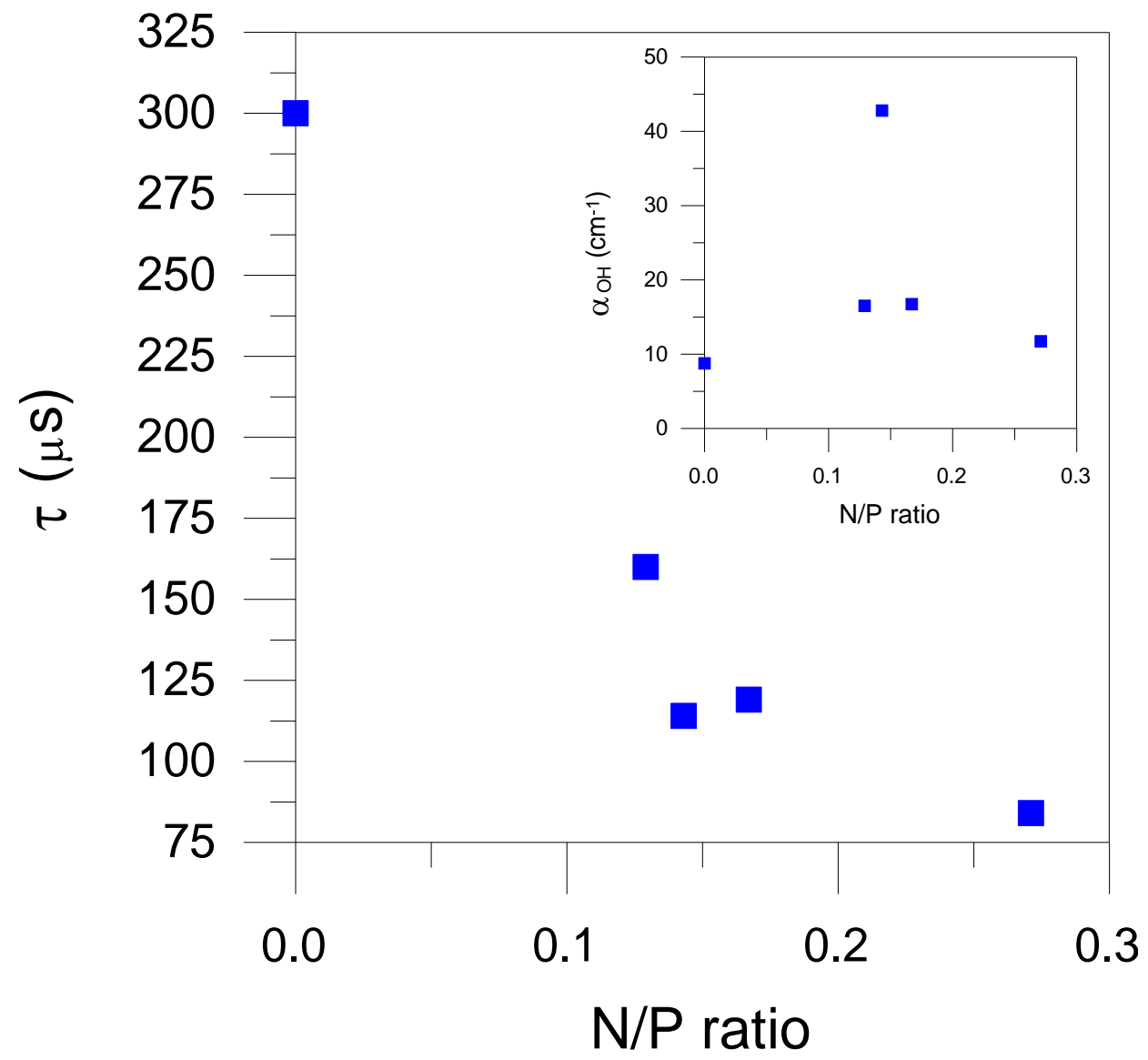

Figure 8 


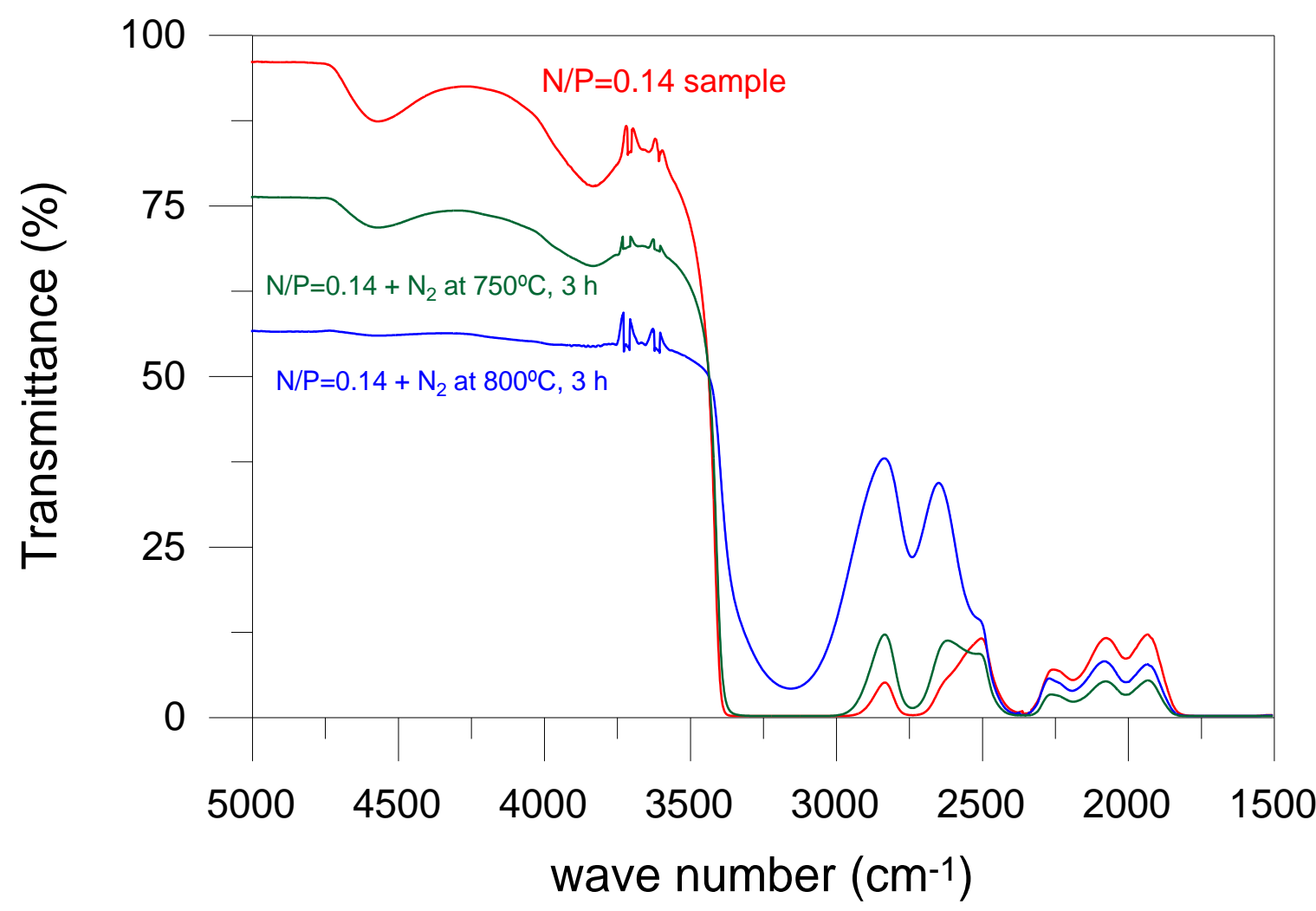

Figure 9 


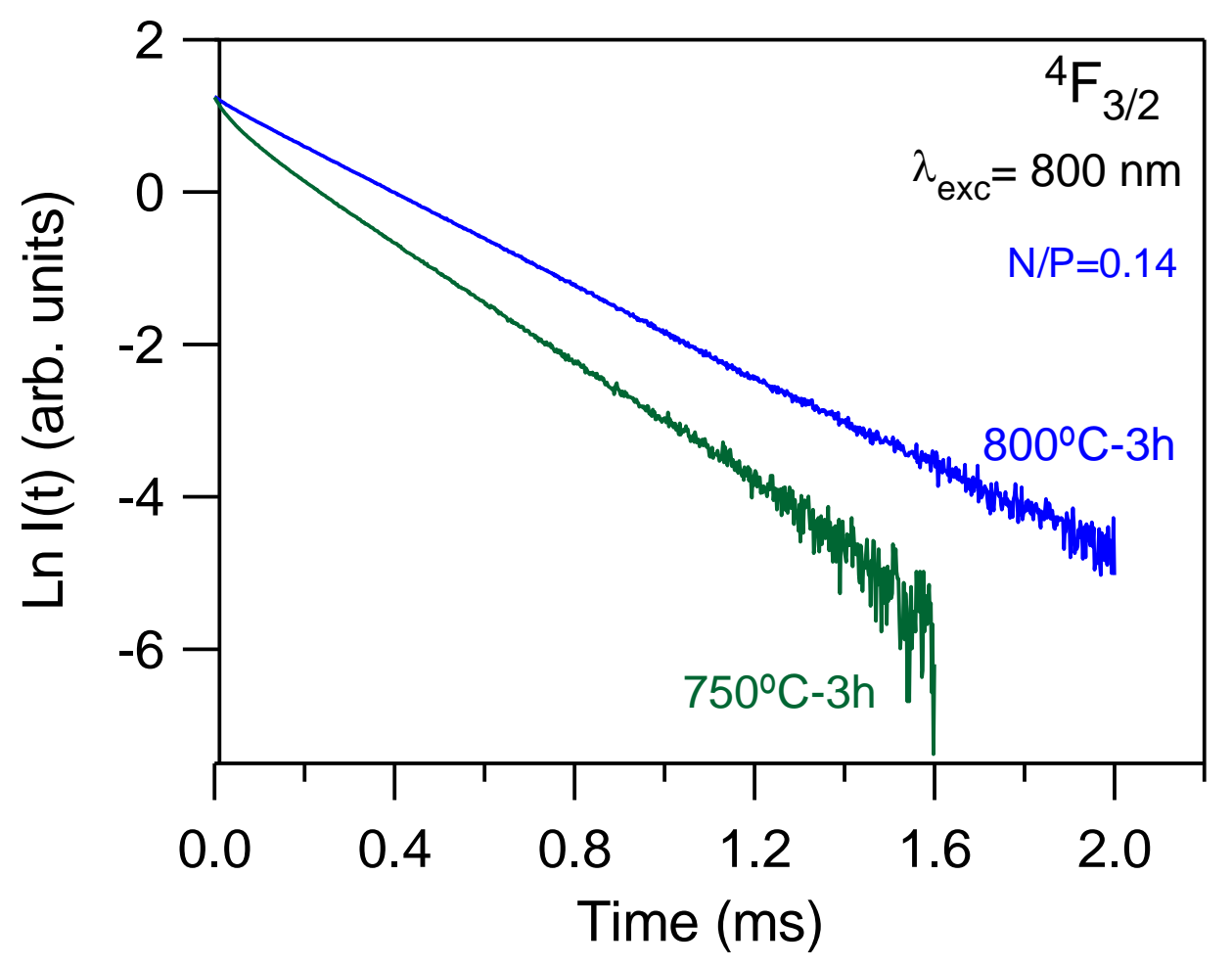

Figure 10 